\title{
CLASSIFICATION OF AURANGABAD CITY USING HIGH RESOLUTION REMOTE SENSING DATA
}

\author{
Kiran Bagade ${ }^{1}$, Second Amol Vibhute ${ }^{2}$, K.V. Kale ${ }^{3}$ \\ ${ }^{I}$ Student Department of Computer Science \& IT, Dr. Babasaheb Ambedkar Marathwada University Aurangabad -431 \\ $004(M S)$ \\ ${ }^{2}$ Student Department of Computer Science \& IT, Dr. Babasaheb Ambedkar Marathwada University, Aurangabad -431 \\ 004 (MS) India \\ ${ }^{3}$ Professor Department of Computer \&IT, Dr. Babasaheb Ambedkar Marathwada University Aurangabad -431 004
}

(MS) India

\begin{abstract}
The current study highlights the advantages of remote sensing and Geographic Information System (GIS) in the field urban planning and management. IRS-P6 Resourcesat-1 LISS-IV high spatial resolution $(5.8 \mathrm{~m})$ data with three spectral bands were used for urban classification. The study area Aurangabad is the capital metro city of Maharashtra State, India. ENVI 4.4 image processing tool was used for classification of satellite data on the basis of supervised approach. Two statistical algorithms were used for urban classification such as Minimum distance and Mahalanobis distance classifier. Lastly the accuracy of the classification was performed through ground truth. The result indicates that the Minimum distance classifier gives the better results than Mahalanobis classifier which are $80.2817 \%$ and $70.4225 \%$ respectively. Hence it is identified minimum distance is best for urban classification.
\end{abstract}

Keywords: Supervised classification, Multispectral, Confusion matrix, Producer's accuracy, Users accuracy.

\section{INTRODUCTION}

Due to rapid growth of population, urbanization, industrialization since World War II, only few landscapes on the earth that are still in their natural state and the agricultural land is decreasing day by day. There is need to convert available lands to agriculture purpose for increasing the food production. From the past two decades, the economic development and population growth have triggered a rapid change to the earth's land cover and the indication shows that the pace of these changes is going to increase in the coming future [1]. Around the entire world, peoples are requesting for environmental monitoring of urban areas. In the urban planning decision-making system, the technical and scientific information is successfully included, but in the technical there are still gaps to be filled. Hence to implement and develop the new tools and techniques which are identified by decision makers, there should be active discussion between technical society and decision makers [2]. It is necessary to improve conventional census of population and old maps through quick, efficient and useful techniques, because of these maps are become out-dated quickly due to expansion of unplanned area and urbanization in the developing countries. Due to population and huge settlements, the conventional data collection, processing and analysis methods cannot give planners and decision-makers with an accurate observation of them. For urban planning, management, marketing analysis, service collection; exact and existing population information is very much crucial in town areas [3], [4].
From the past two decades, remote sensing technology has prepared massive improvement in the sense data accessibility, public knowledge and high resolution multispatial and multi-temporal satellite data which are beneficial for urban land cover classification due to easily availability of high spatial resolution sensors in a timely and costeffective way. Now a day's satellite images combined with GIS has very much improved for various remote sensing applications [5], [6]. For planning and management municipal land use data is most vital, because it is valuable in decision making system. Due to mixed features problem on the earth surface the classification of urban area and identification of land use in urban is quite challenging and consequently the results are not acceptable. Also earth surface features are not directly consequent to the land use classes. Hence the level of urban classification accuracy is decreased which can be solve through high resolution satellite images [7], [8]. Recent days, aerial photography is a key factor of urban planning and management due to availability of latest very high spatial resolution sensors. And high spatial resolution images are more useful than higher spectral resolution because of smaller pixel size to extract urban land cover information [9].

\section{STUDY AREA}

The study area Aurangabad is located on latitude N $19^{\circ} 53^{\prime}$ $47 "$ and E $75^{\circ} 23^{\prime}$ 54" with an area of about $100 \mathrm{~km}$ square which is the capital metro city of Maharashtra State, India. This is the fastest increasing city in the world which is surrounded by hills on all directions as well as lots of 
historical monuments such as Bibi Ka Maqbara, Ajanta and Ellora caves which are UNESCO World Heritage Sites [10]. The data required for the study is obtained from NRSC Balanagar, Hyderabad. Single date, cloud-free IRS-P Resourcesat-I LISS-IV images have been used to classify the study area. This data has three spectral bands which are Band 2 - Green, band 3 - Red, band 4 - NIR with 5.8 meter high spatial resolution. This data is obtained through Linear Imaging and Self Scanning Sensor (LISS) which operates in three spectral bands. The data used in this study was projected to the Universal Transverse Mercator (UTM) and datum was WGS-84. Topographical map are obtained from Survey of India having 1:50,000 scale. For this study here we have used orthocorrected (geometric as well as radiometric corrected) satellite imagery by NRSC, Hyderabad.

Table-1: Used Data

\begin{tabular}{|l|l|l|l|}
\hline Sr.No. & Used Data & Resolution & Data source \\
\hline 01 & IRS-P6, LISS IV & $5.8 \mathrm{~m}$ & $\begin{array}{l}\text { NRSC, } \\
\text { Hyderabad. }\end{array}$ \\
\hline 02 & $\begin{array}{l}\text { Toposheet } \\
: \text { E43D/5 }\end{array}$ & $1: 50,000$ & $\begin{array}{l}\text { Survey Of } \\
\text { India (SOI) }\end{array}$ \\
\hline
\end{tabular}

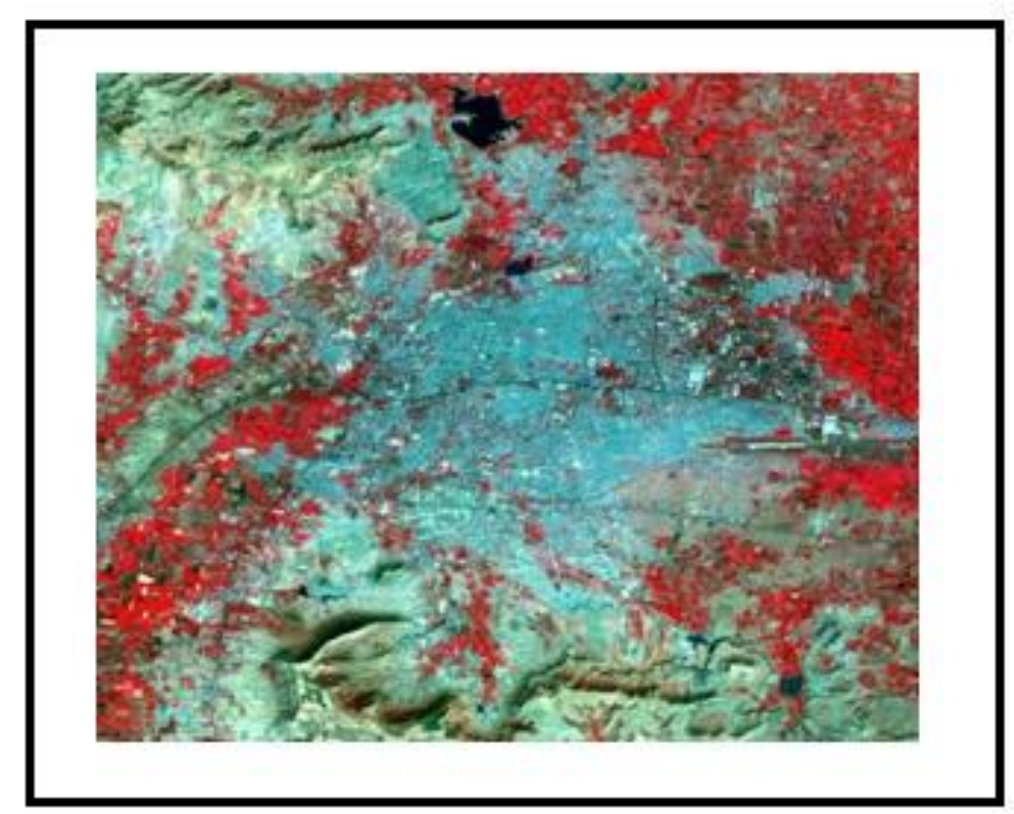

Fig-1: LISS-IV Satellite Image showing study area

\section{METHODOLOGY}

The ENVI 4.4 and ArcGIS 10 software's has been used for visual interpretation and analysis of image.

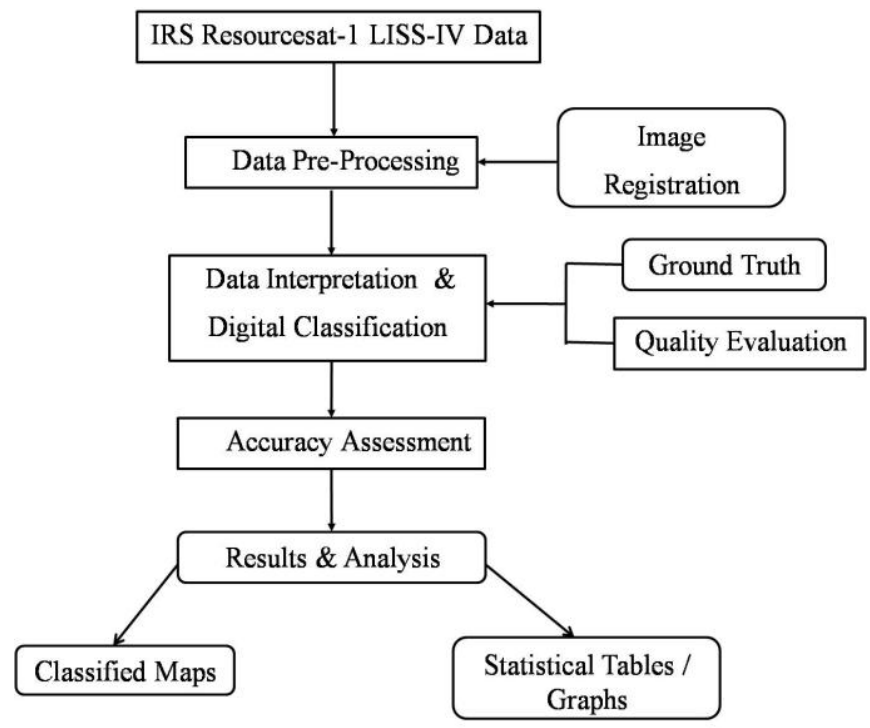

Fig-2: Shows the methodology used in experimentation 
In this study, two different classification algorithms were implemented for urban classification. According to the urban classification scheme supervised approach with the minimum distance classifier and Mahalanobis distance was applied on satellite data to improve the accuracy of the urban classification. Samples of known values were utilized for classifying pixels of unknown values in supervised classification. Hence this classification is depending on the training pixels, which creates essential to have knowledge of the land cover and spectral reflectance of the interested region [13]. For representing typical spectral information, training sets in the image are created of the land cover classes, like buildings, open space, hilly area, barren land and agricultural land etc. There are lots of techniques for classification, which consist of minimum distance to mean classifier, parallelepiped classifier, mahalanobis classifier and maximum likelihood classifier.

\subsection{Minimum Distance Classifier}

The minimum distance classifier utilizes mean vector in every class spectral reflectance to classify unknown image data to classes. It minimizes the space between the class in multi feature space and the image statistics. The minimum distance is equal to the maximum relationship because of the distance is defined as an index of similarity [13].

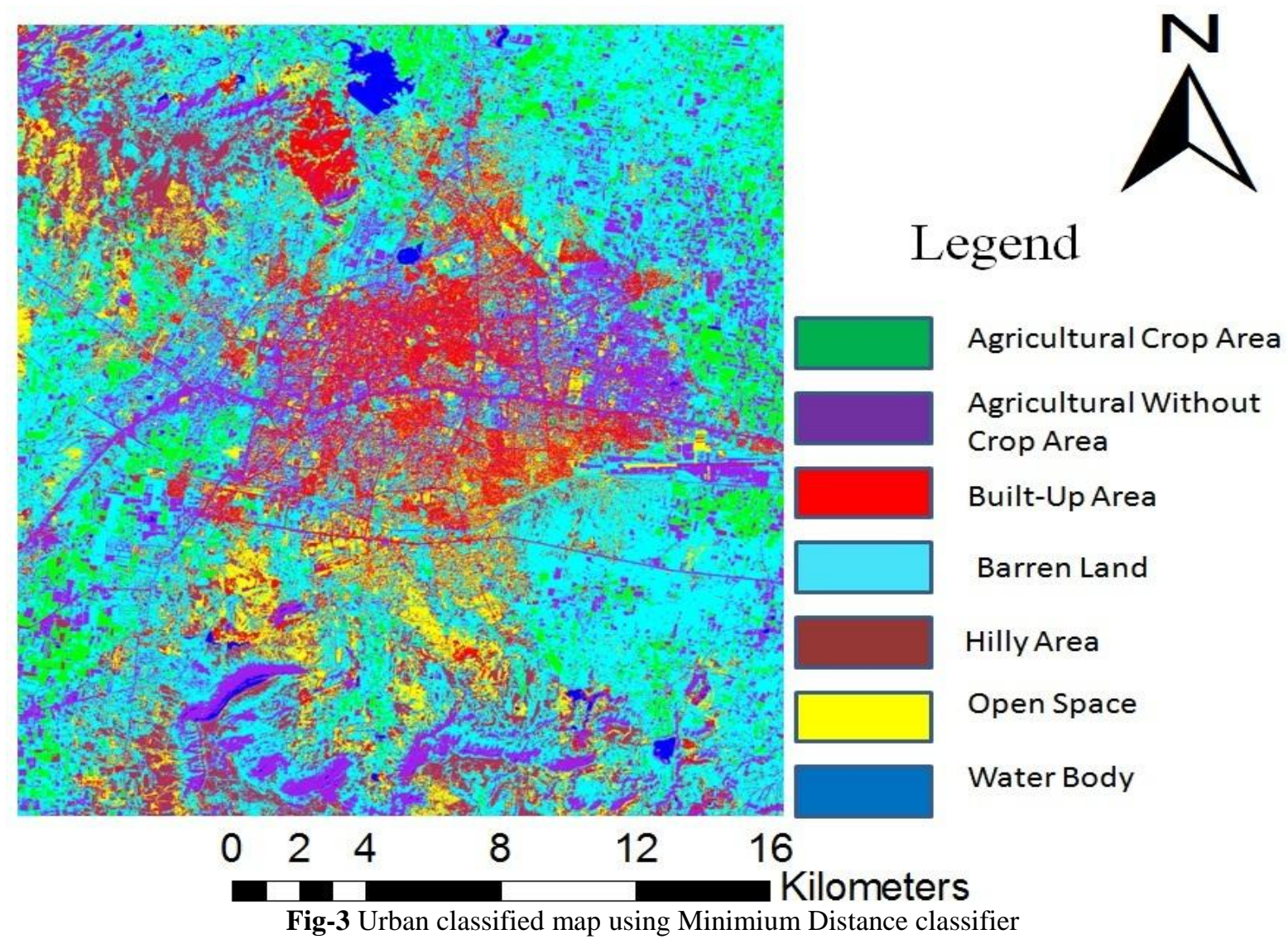

Table 3: Area and percentage of land use/land cover classes using Minimium distance classifier

\begin{tabular}{|l|l|l|}
\hline \multirow{2}{*}{ Categories } & \multicolumn{2}{l|}{ Minimum Distance Classifier } \\
\cline { 2 - 3 } & \multicolumn{2}{|l|}{} \\
\cline { 2 - 3 } & Area (in Acres) & Area (\%) \\
\hline Agricultural Crop Area & $4,109.2036$ & 7.391 \\
\hline Agriculture Area without Crops & $9,685.4225$ & 17.420 \\
\hline Built-up Area (Buildings) & $6,158.7737$ & 11.077 \\
\hline Barren Land & $25,101.0595$ & 45.147 \\
\hline Open Space & $5,200.3176$ & 9.353 \\
\hline Hilly Area & $4,880.8364$ & 8.779 \\
\hline Water Bodies & 462.8697 & 0.833 \\
\hline Unclassified & 0.00 & 0.00 \\
\hline Total Area & $\mathbf{5 5 , 5 9 8 . 4 8 3}$ & $\mathbf{1 0 0 . 0 0}$ \\
\hline
\end{tabular}




\subsection{Mahalanobis Distance Classifier}

This classifier based on the correlations between variables by which different patterns can be identified and analyzed. It measures the similarity of an unknown sample set to a known one.

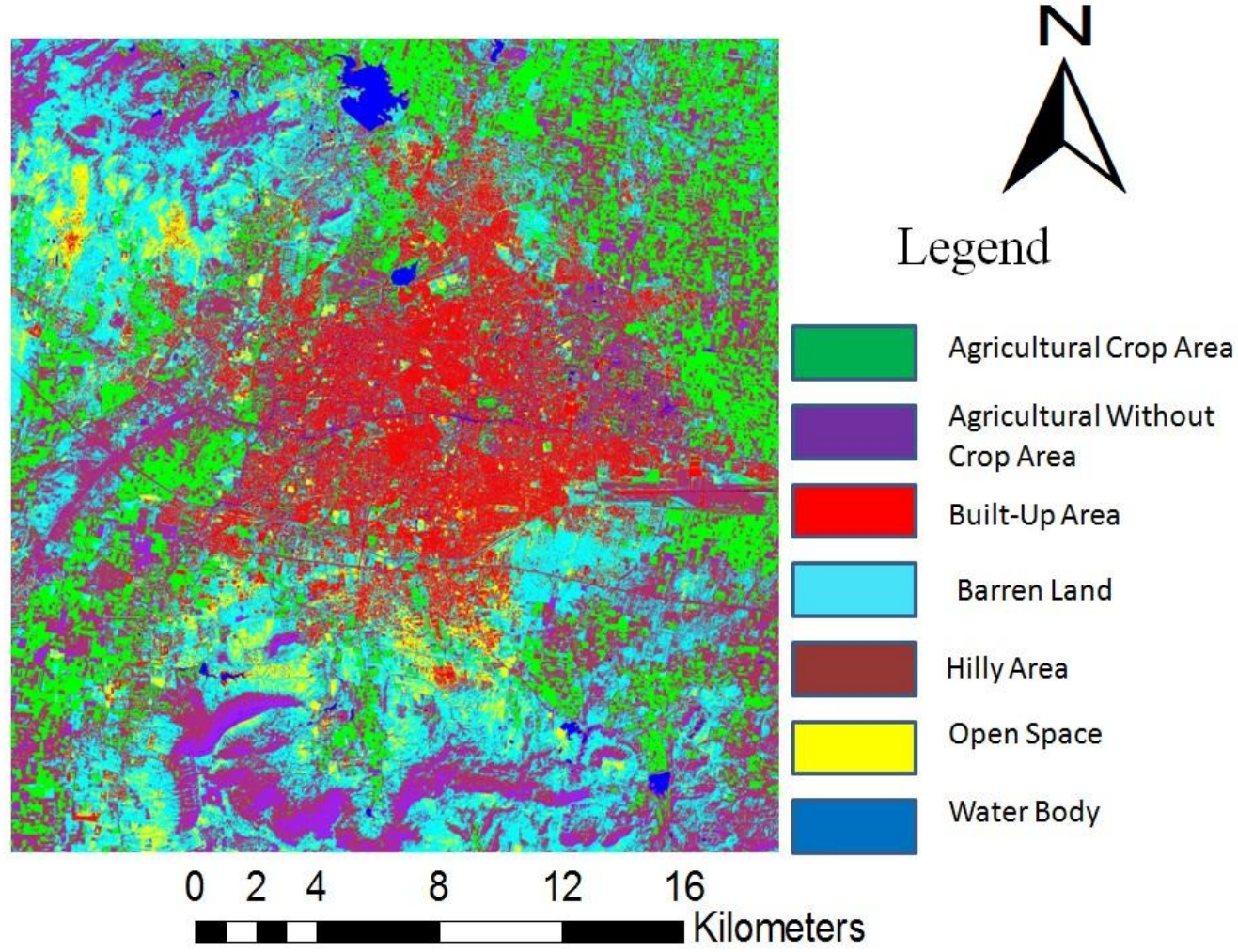

Fig-4 Urban classified map using Mahalanobis classifier

Its approach is different from Euclidian distance. It takes into account the correlations of the data set and is scale-invariant [13].

Table -4: Area and percentage of land use/land cover classes using Mahalanobis classifier

\begin{tabular}{|l|l|l|}
\hline \multirow{2}{*}{ Categories } & \multicolumn{2}{|l|}{ Mahalanobis Classifier } \\
\cline { 2 - 3 } & Area (in Acres) & Area (\%) \\
\hline Agricultural Crop Area & $9,679.6835$ & 17.410 \\
\hline Agriculture Area without Crops & $2,764.6037$ & 4.972 \\
\hline Built-up Area (Buildings) & $8,146.4874$ & 14.652 \\
\hline Barren Land & $15,783.6680$ & 28.389 \\
\hline Open Space & $2,835.4856$ & 5.100 \\
\hline Hilly Area & $15,681.3174$ & 28.205 \\
\hline Water Bodies & 707.2374 & 1.272 \\
\hline Unclassified & 0.00 & 0.00 \\
\hline Total Area & $\mathbf{5 5 , 5 9 8 . 4 8 3}$ & $\mathbf{1 0 0 . 0 0}$ \\
\hline
\end{tabular}

\section{ACCURACY ASSESSMENT}

For accuracy assessment ground control points are essential. The classification accuracy is calculated using training sites confusion matrix or error matrix in terms of producer's accuracy, user's accuracy and overall accuracy with kappa coefficient.

Table -5: Error matrix for Minimium distance classifier

\begin{tabular}{|c|c|c|c|c|c|c|c|c|}
\hline \multirow[t]{2}{*}{ Class } & \multicolumn{8}{|c|}{ Ground Truth (Pixels) } \\
\hline & ALC & ALWC & $\mathrm{BD}$ & BL & OS & HA & WB & Total \\
\hline Agricultural Crop Area & 0 & 0 & 0 & 0 & 0 & 0 & 0 & 0 \\
\hline $\begin{array}{l}\text { Agriculture Area without } \\
\text { Crops }\end{array}$ & 10 & 0 & 0 & 0 & 1 & 0 & 0 & 11 \\
\hline Built-up Area (Buildings) & 0 & 10 & 0 & 0 & 0 & 1 & 0 & 11 \\
\hline
\end{tabular}




\begin{tabular}{|l|l|l|l|l|l|l|l|l|}
\hline Barren Land & 0 & 0 & 9 & 0 & 0 & 1 & 0 & 10 \\
\hline Open Space & 0 & 0 & 0 & 5 & 7 & 5 & 0 & 17 \\
\hline Hilly Area & 0 & 0 & 2 & 0 & 5 & 1 & 0 & 8 \\
\hline Water Bodies & 0 & 0 & 0 & 3 & 0 & 2 & 0 & 5 \\
\hline Unclassified & 0 & 0 & 0 & 0 & 0 & 0 & 9 & 9 \\
\hline Total & 10 & 10 & 11 & 8 & 13 & 10 & 9 & 71 \\
\hline
\end{tabular}

OS- OPEN SPACE ,WB -Water Body, BD-Buildings, HA-Hill Area, BL-Barren Land, ALWC-Agricultural Land Without Crop, ALC-Agricultural Land With Crop,

To map classified labels original ground control points for a sample of pixels at specified site, confusion matrix can be utilized. The accuracy assessment is examined to be one of the vital measurements of the study for accessing consistency of the classified map [13].

Table -5: Error matrix for Mahalanobis distance classifier

\begin{tabular}{|l|l|l|l|l|l|l|l|l|}
\hline \multirow{2}{*}{ Class } & \multicolumn{2}{|l}{ Ground Truth (Pixels) } \\
\cline { 2 - 10 } & ALC & ALWC & BD & BL & OS & HA & $\begin{array}{l}\text { W } \\
\text { B }\end{array}$ & Total \\
\hline Agricultural Crop Area & 0 & 0 & 0 & 0 & 0 & 0 & 0 & 0 \\
\hline $\begin{array}{l}\text { Agriculture Area } \\
\text { without Crops }\end{array}$ & 8 & 0 & 0 & 0 & 1 & 0 & 0 & 9 \\
\hline $\begin{array}{l}\text { Built-up } \\
\text { (Buildings) }\end{array}$ & 0 & 10 & 1 & 0 & 0 & 0 & 0 & 11 \\
\hline Barren Land & & & & & & & & \\
\hline Open Space & 0 & 0 & 5 & 0 & 0 & 1 & 0 & 6 \\
\hline Hilly Area & 2 & 0 & 1 & 8 & 0 & 2 & 0 & 13 \\
\hline Water Bodies & 0 & 0 & 3 & 0 & 11 & 1 & 0 & 15 \\
\hline Unclassified & 0 & 0 & 1 & 0 & 1 & 6 & 0 & 8 \\
\hline Total & 0 & 0 & 0 & 0 & 0 & 0 & 9 & 9 \\
\hline
\end{tabular}

According to accuracy assessment results, for the minimum distance classifier overall accuracy was $80.2817 \%$ and Kappa Coefficient was 0.7696. Mahalanobis distance classifier overall accuracy was $70.4225 \%$ and Kappa Coefficient was 0.6565.

Table -6: Accuracy assessment of two classifiers (in \%)

\begin{tabular}{|c|c|c|c|c|c|c|}
\hline \multirow{2}{*}{ Classes } & \multicolumn{3}{|c|}{ Minimum Distance Classifier } & \multicolumn{3}{|c|}{ Mahalanobis Classifier } \\
\hline & PA & UA & $\mathrm{OA}$ & PA & UA & $\mathrm{OA}$ \\
\hline $\begin{array}{l}\text { Agriculture Crop } \\
\text { Area }\end{array}$ & 80.00 & 88.89 & \multirow{7}{*}{80.2817} & 100.00 & 90.91 & \multirow{7}{*}{70.4225} \\
\hline $\begin{array}{l}\text { Agriculture } \\
\text { without crops }\end{array}$ & 100.00 & 90.91 & & 100.00 & 90.91 & \\
\hline $\begin{array}{l}\text { Built up Area } \\
\text { (Buildings) }\end{array}$ & 45.45 & 83.33 & & 81.82 & 90.00 & \\
\hline Barren Land & 100.00 & 61.54 & & 62.50 & 29.41 & \\
\hline Open Space & 84.62 & 73.33 & & 38.46 & 62.50 & \\
\hline Hilly Area & 60.00 & 75.00 & & 20.00 & 40.00 & \\
\hline Water Body & 100.00 & 100.00 & & 100.00 & 100.00 & \\
\hline
\end{tabular}

PA-Producers Accuracy, A-Users Accuracy, A-Overall Accuracy

\section{RESULTS AND DISCUSSION}

The major target of the classification is to differentiate the study area into different thematic classes. The results obtained from this study shows that IRS-P6 Resourcesat-I LISS-IV to be reliable data source for urban classification. The final result shows that, seven different classes were obtained through image classification. 


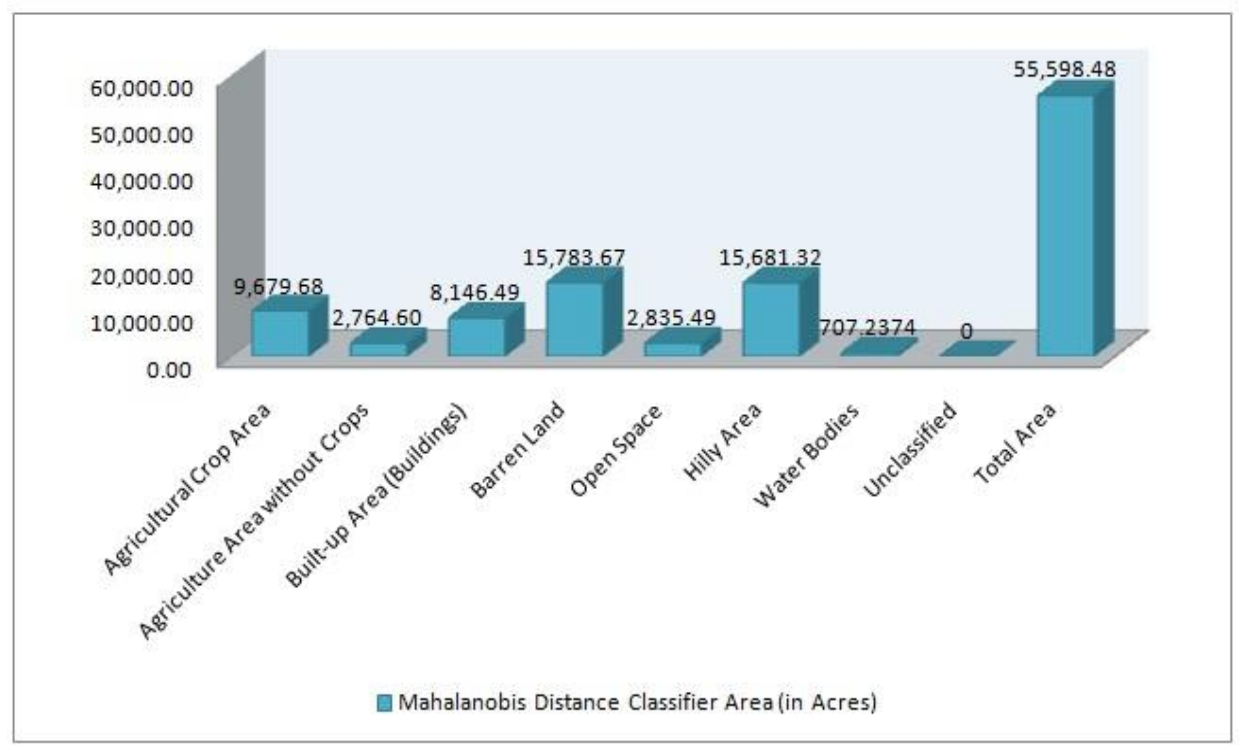

Fig-5: Area of urban land cover in hectares using Mahalanobis classifier

\subsection{Agricultural Area:}

The agricultural area from the satellite data classification could be clearly explained in two classes such as agricultural crop area and agricultural area without crops. The area covered by the crops is near about 4,109.2036 Acres (7.391\%), while without crops as near about 9,685.4225 Acres $(17.420 \%)$ by minimum distance classifier. And through the Mahalanobis classifier it is shown that, agricultural crops are near about 9,679.6835 Acres (17.410\%) and only 2,764.6037 Acres (4.972\%) area is agriculture without crops.

\subsection{Barren Land and Open Space:}

The land is dry and bare, and has very few plants and no trees are generally known as barren land. Near about 25,101.0595 Acres $(45.147 \%)$ area is under the barren land and 5,200.3176 Acres $(9.353 \%)$ is open space through minimum distance classification, where as 15,783.6680 Acres (28.389\%), 2,835.4856 Acres (5.100\%) barren area and open space area is classified by Mahalanobis distance classifier respectively.

\subsection{Built-up Area:}

It is identified as an area of human habitation developed due to non-agriculture use and has a cover of buildings transport and other utilities. Hence the built-up area is 6,158.7737 Acres (11.077\%) via minimum distance classifier, whereas 8,146.4874 Acres $(14.652 \%)$ area is covered by Mahalanobis classifier.

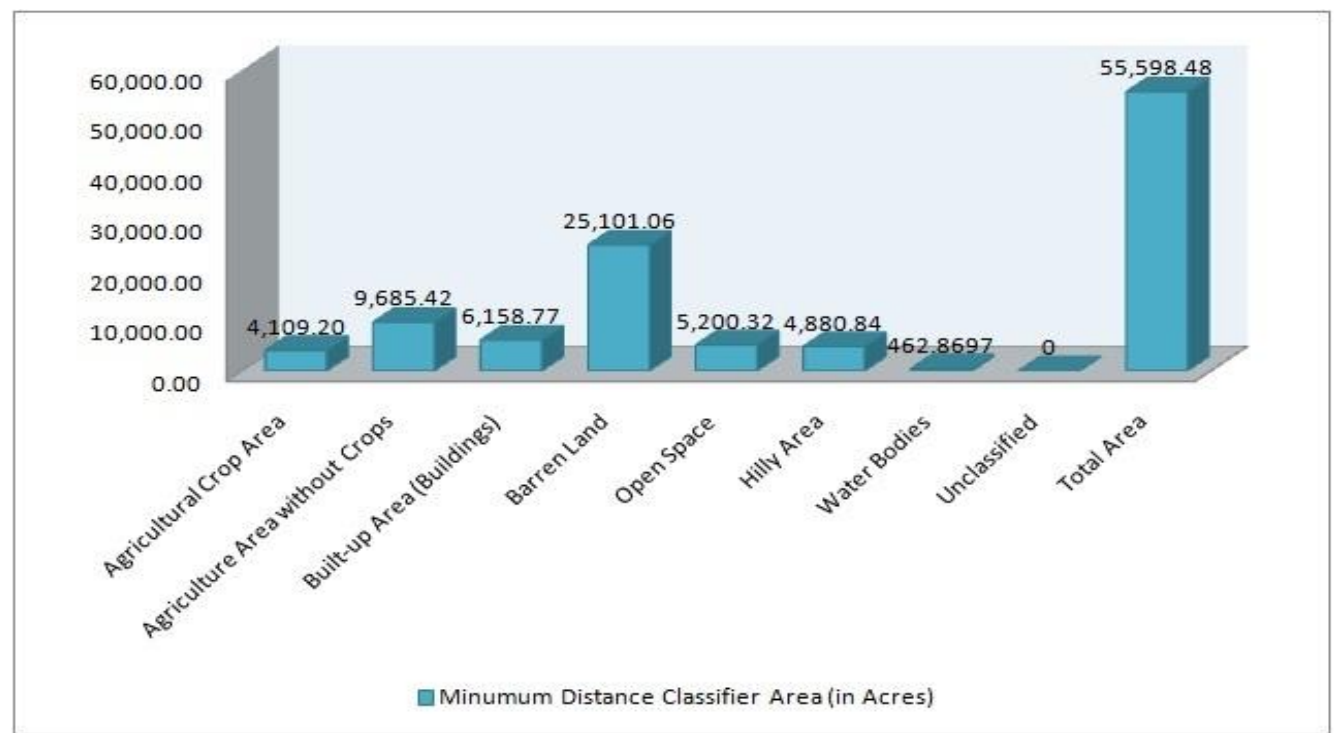

Fig-6: Area of urban land cover in hectares using Minimium Distance classifier 


\subsection{Hilly Area}

Hilly area is considered as landform that extends above the surrounding terrain. There are three categories of hilly area such as hill with trees, hill with rocks and hill without trees. Here minimum distance classifier classifieds 4,880.8364 Acres $(8.779 \%)$ area of overall hilly part and near about 15,681.3174 Acres (28.205\%) area is classified by Mahalanobis distance classifier.

\subsection{Water Bodies}

This category includes area with water either impounded in the form of lakes and dams etc. It occupied total area of water bodies in the region is 462.8697 Acres $(0.833 \%)$ through minimum distance classifier, whereas 707.2374 Acres $(1.272 \%)$ area is classified by Mahalanobis classifier.

\subsection{Agricultural Area without Crop}

This category includes Agricultural area without crop area.It occupied total area of Agricultural area without crop in the region is 9,685.4225Acres (17.420\%) through minimum distance classifier, whereas 2,764.6037Acres (4.972\%) area is classified by Mahalanobis classifier.

\section{CONCLUSION}

The present study can explain the trend of burden and stress of a farming land to become non-farming land or to become small yielding land because of town expansion. The study clearly recognized that the satellite remote sensing joined with GIS can be a dominant tool for urban planning and management. This study illustrates that the minimum distance algorithm is a good choice for image classification based on high spatial resolution image. Various techniques were used for urban classification based on various statistical parameters. The accuracies of the minimum distance and Mahalanobis distance classification are evaluated through the reference data from a ground survey. It observed that the minimum distance classification approach outperformed the Mahalanobis distance classification approach for urban classification.

\section{REFERENCES:}

[1]. Meliadis Ioannis, Miltiadis Meliadis, "Multi-temporal Landsat image classification and change analysis of land cover/use in the Prefecture of Thessaloiniki, Greece", Proceedings of the International Academy of Ecology and Environmental Sciences, vol. 1(1), pp. 15-25, 2011.

[2]. Paolo GAMBA, Fabio DELL'ACQUA, "MONITORING URBAN AREAS FOR ENVIRONMENT AND SECURITY THROUGH REMOTE SENSING", Dipartimento di Elettronica, Universit'a di Pavia, Via Ferrata, 1, I-27100 Pavia, Italy.

[3]. Roshanak DARVISHZADEH, "Change Detection for Urban Spatial Databases Using Remote Sensing and GIS", International Archives of Photogrammetry and Remote Sensing. Vol. XXXIII, Part B7, Amsterdam 2000.

[4]. Fang Qiu, Kevin L. Woller, and Ronald Briggs, "Modeling Urban Population Growth from Remotely Sensed
Imagery and TIGER GIS Road Data", Photogrammetric Engineering \& Remote Sensing Vol. 69, No. 9, September 2003, pp. 1031-1042.

[5]. W. Tadesse, T. L. Coleman, and T.D. Tsegaye, "Improvement of Land Use and Land Cover Classification of an Urban Area Using Image Segmentation from Landsat ETM+ Data", Center for Hydrology, Soil Climatology, and Remote Sensing, Department of Plant and Soil Science; Alabama A\&M University, P.O. Box 1208, Normal, AL 35762.

[6]. Limin Yang, George Xian, Jacqueline M. Klaver, and Brian Deal, "Urban Land-Cover Change Detection through Sub-Pixel Imperviousness Mapping Using Remotely Sensed Data",

[8]. Victor Mesev, "The Use of Census Data in Urban Image Classification", Photogrammetric Engineering \& Remote Sensing, Vol. 64, No. 5, May 1998, pp. 431-438.

[9]. Soe W. Myint a, Patricia Gober a, Anthony Brazel a, Susanne Grossman-Clarke b,d, Qihao Weng c a School, "Per-pixel vs. object-based classification of urban land cover extraction using high spatial resolution imagery", Remote Sensing of Environment, Elsevier Inc.2011.

[10].http://en.wikipedia.org/wiki/Aurangabad,_Maharashtra. [11]. http://www.mapsofindia.com/maps/maharashtra/tehsil/. [12].http://www.mapsofindia.com/maps/maharashtra/district s/aurangabad.htm.

[13]. Amol D. Vibhute, Dr. Bharti W. Gawali, "Analysis and Modeling of Agricultural Land use using Remote Sensing and Geographic Infor-mation System: a Review", International Journal of Engineering Re-search and Applications (IJERA), vol. 3(3), pp. 081-091, May-Jun 2013.

\section{BIOGRAPHIES}

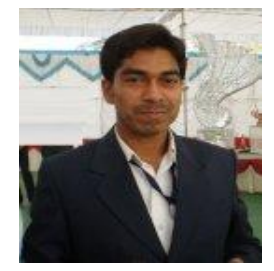

Awarded M.Phil (Computer Science) in Department of Computer Science \& IT, Dr. Babasaheb Ambedkar Marathwada, University, Aurangabad, in 2013, with Distinction (79\%). M. Sc (Computer Science) from Department of Computer Science \& IT, Dr. Babasaheb Ambedkar Marathwada, University, Aurangabad, in 2011, with First Division (75\%).B. Sc from Dr. Babasaheb Ambedkar Marathwada University, Aurangabad, in 2008, with First Division (65\%).

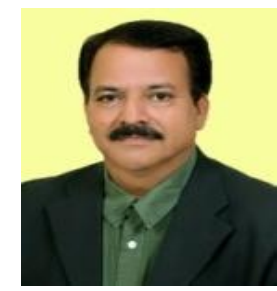

Dr. K.V. KALE is M.Sc, MCA, Ph.D. SMIEEE, FIETE, Presently working as a Professor and Head, Department of Computer Science and Information Technology, Dr Babasaheb Ambedkar Marathwada University,Aurangabad, MS-India. He is a fellow of IETE, SSARSC,Life member of CSI, IAPR, ISCA, IACSIT, IAENG, IEEE and elevated senior member of IEEE. He is a member \& Faculty of Board of Studies of various universities in India \& has designed and implemented new courses in computer science at UG \& PG level. He is recipient of VIJAY SHREE Award. He is actively engaged in research and development. $\mathrm{He}$ has more 
than $\mathbf{2 4 0}$ research papers to his credit which are published in reputed national/international journals and conferences and $\mathbf{4}$ books to his credit. Under his able guidance21 $P h D$ students have completed their $\mathrm{PhD}$ and 9 students are still doing $\mathrm{PhD}$ under his guidance.

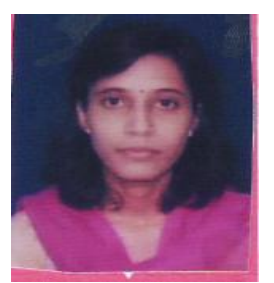

Kiran Bagde received his Bachelor's Degree in Computer science and engineering from PES college of engineering Aurangabad in 2008 ,with Distinction (75.56\%). Currently she is pursuing his Master's in Computer Science \& Engineering from

Department of CS \& IT, Dr. Babasaheb Ambedkar Marathwada University, Aurangabad. Her research interest includes GIS and REMOTE SENSING etc. 